\title{
The role of biologics in the treatment of giant cell arteritis
}

\section{Miguel A. González-Gay, Trinitario Pina, Diana Prieto-Peña, Mónica Calderon- Goercke, Ricardo Blanco \& Santos Castañeda}

To cite this article: Miguel A. González-Gay, Trinitario Pina, Diana Prieto-Peña, Mónica CalderonGoercke, Ricardo Blanco \& Santos Castañeda (2018): The role of biologics in the treatment of giant cell arteritis, Expert Opinion on Biological Therapy, DOI: 10.1080/14712598.2019.1556256

To link to this article: https://doi.org/10.1080/14712598.2019.1556256

Accepted author version posted online: 04

Dec 2018.

Submit your article to this journal $₫$

View Crossmark data [ 
Publisher: Taylor \& Francis

Journal: Expert Opinion on Biological Therapy

DOI: $10.1080 / 14712598.2019 .1556256$

The role of biologics in the treatment of giant cell arteritis

Miguel A. González-Gay ${ }^{1,2,3^{*}}$, Trinitario Pina ${ }^{1}$ Diana Prieto-Peña ${ }^{1}$, Mónica Calderon-

Goercke$^{1}$, Ricardo Blanco ${ }^{1}$, Santos Castañeda ${ }^{4}$.

\section{Affiliations:}

${ }^{1}$ Division of Rheumatology and Epidemiology, Genetics and Atherosclerosis Research Group on Systemic Inflammatory Diseases, Hospital Universitario Marqués de Valdecilla, IDIVAL, Santander, Spain.

${ }^{2}$ University of Cantabria, Santander, Spain.

${ }^{3}$ Cardiovascular Pathophysiology and Genomics Research Unit, School of Physiology, Faculty of Health Sciences, University of the Witwatersrand, Johannesburg, South Africa.

${ }^{4}$ Rheumatology Division, Hospital de La Princesa, IIS-Princesa, Universidad Autónoma de Madrid (UAM), Madrid, Spain.

Miguel A.González-Gay, M.D, PhD. E-mail: miguelaggay@hotmail.com

Trinitario Pina, MD, PhD. E-mail: trinitario.pina@scsalud.es

Diana Prieto-Pena, MD. E-mail: diana.prieto@scsalud.es

Mónica Calderón-Goercke, MD. E-mail: monica.calderon@scsalud.es

Ricardo Blanco, MD, PhD. E-mail: ricardo.blanco@scsalud.es

Santos Castañeda, MD, PhD. E-mail: scastas@gmail.com

\section{*Correspondence to:}


Prof. Miguel A. González-Gay, Professor of Medicine, University of Cantabria, Rheumatology, Division and Epidemiology, Genetics and Atherosclerosis Research Group on Systemic Inflammatory Diseases, Hospital Universitario Marqués de Valdecilla, IDIVAL, Avenida Cardenal Herrera Oria s/n 39011 - Santander, Spain.

\section{Abstract}

Introduction: Giant cell arteritis is a vasculitis of large and middle-sized arteries that affects individuals older than 50 years. Although glucocorticoids remain the mainstay in the treatment of this vasculitis, other drugs are often required to achieve clinical remission and allow glucocorticoid discontinuation.

Areas covered: The review summarizes the main biologic therapies used for the managements of GCA.

Expert commentary: Although several biologic agents have been used in patients with GCA, the only biologic agent currently approyed for this purpose is the recombinant humanized anti-IL-6 receptor antibody: tocilizumab. It has demonstrated efficacy to improve clinical symptoms, decrease the cumulative prednisone dose and reduce the frequency of relapses in clinical trials and real-life studies on patients with GCA. A trial showed that abatacept may be useful to maintain remission in GCA patients. An openlabel study suggested that ustekinumab could be useful for the treatment of patients with refractory GCA. However, further studies are required to confirm if both abatacept and ustekinumab are useful as an adjunctive therapy to reduce relapses or as a glucocorticoid sparing agent in GCA. Anakinra has been successfully used in a few patients with refractory GCA. In contrast, anti-tumor necrosis factor- $\alpha$ therapy yielded disappointing results in GCA. 
Keywords: abatacept, anti-IL6-receptor tocilizumab, giant cell (temporal) arteritis, methotrexate, prednisone, relapses.

\section{Introduction}

Giant cell arteritis (GCA) is a granulomatous vasculitis that affects large and middlesized arteries. It occurs in people 50 years and older, being the most common vasculitis in elderly people from Europe and North America, in particular in those of Scandinavian background [1,2]. The highest incidence of GCA is observed in the 70-80 age group [3].

The etiology of GCA is unknown. Infectious and other unidentified environmental factors in individuals genetically predisposed trigger a systemic inflammatory response leading to a dysregulation of the immune system involving Th1 and Th17 lymphocyte subpopulations with the overproduction of pro-inflammatory cytokines such as interleukin (IL)-1, IL-6, IL-17, interferon (IFN)- $\gamma$ and, to a lesser extent, tumor necrosis factor (TNF)- $\alpha[1,2,4]$.

Histopathological changes in blood vessels from patients with GCA include the presence of a mononuclear inflammatory infiltrate that can affect all layers of the arterial wall, with or without multinucleated giant cells along with disruption of the internal elastic lamina and vascular remodeling signs with destruction of the arterial wall, intimal hyperplasia and neoangiogenesis. Arterial damage leads to partial or complete obstruction of local arterial blood flow with the corresponding clinical manifestations of ischemia $[4,5]$.

Typical cranial symptoms include an abrupt onset of headache, scalp tenderness, jaw claudication or more rarely tongue claudication, dry cough or sore throat due to arteritis 
involvement of branches derived of the external carotid artery [2,6]. GCA patients may suffer visual manifestations, such as amaurosis fugax or permanent visual loss, which are generally due to involvement of the posterior ciliary arteries that are branches of the internal carotid artery [7]. Patients with GCA have an increased risk of developing aneurysms and dissection over the course of the disease, especially in the thoracic segment of the aorta $[\mathbf{8 , 9}$. In a recent study, structural damage in the aorta affected up to $33.3 \%$ of individuals after long term follow-up [10]. Once aortic structural damage occurs, dilatation increases over time, underlining the need for periodic evaluation [10]. GCA patients often have polymyalgia rheumatica (PMR) features that may be occur before, simultaneously or after the diagnosis of GCA has been established [11]. A small proportion of patients with GCA may suffer strokes that affect more often the vertebrobasilar territory at early stages and the carotid branches during follow-up [12]. Additionally, patients with GCA often have non-specific clinical features, such as lowgrade fever, malaise, asthenia, and weight loss [13].

A physical examination may disclose thickening, tenderness or reduced pulsation of the temporal arteries [14]. Pulse deficits, bruits or asymmetric arterial pressure measurements in any of the four limbs may also be observed in patients with extracranial large-vessel involvement [8].

Most patients have abnormality of acute phase reactants (erythrocyte sedimentation rate [ESR] and C reactive protein [CRP]) [15]. However, there is a small subgroup ( 5\%) with normal inflammatory markers, who are more likely to be overlooked, reason why they may be at increased risk of visual loss. Anemia, high platelet count and elevation of hepatic function tests may also be frequently observed $[2,15]$. Patients with GCA often experience relapses that present with manifestations of the disease such as headache or other cranial manifestations, PMR, fever or constitutional 
symptoms. Relapses are generally associated with elevation of acute phase reactants [16]. They constitute a challenge for the clinician since they may occur in almost $50 \%$ of the patients when glucocorticoid therapy is tapered [17].

Although a temporal artery biopsy showing the typical inflammatory infiltrate has been considered the gold-standard tool for the diagnosis [5], color duplex ultrasonography showing arterial wall edema (the "halo sign") has been proposed as alternative to temporal artery biopsy in patients presenting with the typical cranial pattern of GCA $[\mathbf{6 , 1 8}]$. Other imaging techniques, such as the magnetic resonance, computed tomography (CT)-angiography, and [18F]-fluorodeoxyglucose (FDG)-positron emission tomography (PET/CT) are useful to diagnose patients with predominant extracranial manifestations $[\mathbf{1 9 , 2 0}]$. Interestingly, in these cases with predominant large-vessel vasculitis without cranial involvement a temporal artery biopsy often yields negative results [21].

\section{Areas covered}

Glucocorticoids are the cornerstone of treatment of GCA $[4,5]$. Conventional immunosuppressive drugs, mainly methotrexate (MTX), have been used as glucocorticoid-sparing agents and to reduce the frequency of relapses. However, results in terms of efficacy have not been well established [22].

A recent review summarized the most common conventional immunosuppressive drugs used in patients with GCA [23]. According to data shown in this review, MTX is still the most commonly used conventional immunosuppressive drug for the management of refractory GCA. However, the efficacy of this drug in GCA is modest [23]. Also, the experience with other conventional immunosuppressive drugs in GCA patients is small and of limited relevance [23]. 
In the present review, we have focused on the use of biologic agents in GCA.

Information on the recently approved use of the anti-IL-6 receptor tocilizumab is discussed in depth. The potential efficacy of other biologic agents is also discussed.

\subsection{Role of the biologic agents in the management of GCA}

\section{1.1. Anti-tumor necrosis factor (TNF) therapy: Disappointing results}

Anti-TNF- $\alpha$ agents proved efficacy in patients with inflammatory arthritis. In addition, there are some evidences that TNF- $\alpha$ could play a pathogenic role in this disease [2426]. Because of that, anti-TNF- $\alpha$ drugs were also tested in patients with GCA. However, the results turned out to be negative to maintain remission in newly diagnosed patients. Hoffman et al. conducted the most important study that consisted of a phase II study, randomized, double-blind, placebo-controlled trial to determine the efficacy of the chimeric monoclonal antibody-infliximab in GCA patients with new onset disease [27]. The study included 44 patients that had obtained resolution of symptoms and normalization of ESR following treatment with $40-60 \mathrm{mg} /$ day of prednisone/prednisolone. For the inclusion in the study patients required to have been in remission of the disease for at least 1 week before randomization [27]. Patients received an initial dose of 40-60 mg/prednisone/day and they were randomized to receive either placebo $(\mathrm{n}=16)$ or infliximab $5 \mathrm{mg} / \mathrm{kg} /$ infusion $(\mathrm{n}=28)$ at baseline (week 0$)$ and at weeks $2,6,14,22,30,38$ and 46 . However, there were no differences between both groups after 22 weeks of follow-up. Infliximab-did not yield significant reduction in the cumulative doses of prednisone or in the number of patients free of relapses [27]. With respect to the efficacy of other TNF-antagonists the information is scarce and roughly negative in terms of efficacy. A study using the human anti-TNF monoclonal antibody adalimumab given for 10 weeks to GCA patients of recent diagnosis did not show 
efficacy to reach remission with a dose of less than $0.1 \mathrm{mg} / \mathrm{kg}$ of prednisone at 6 months. In addition, those who received adalimumab had more infections [28]. Information on another TNF-antagonist, etanercept, is also limited to a pilot study that did not confirm efficacy in patients with GCA [29].

\subsubsection{Interleukin (IL)-6 inhibitors: Tocilizumab approved for the management of}

\section{$G C A$}

IL-6 is a pivotal proinflammatory cytokine that is produced in the inflamed arteries of patients with GCA [30]. It is also expressed in the monocytes of these patients [31]. GCA patients have increased IL-6 serum levels [32,33]. IL-6 concentration is closely related to disease activity and the CRP level. Persistence of high serum IL-6 levels suggests the presence of disease activity in glucocorticoid-treated patients with GCA [33]. Dasgupta and Panayi highlighted for first time that the use of glucocorticoids led to a rapid reduction of the levels of IL-6 in patients with GCA [34]. Since such a reduction of IL-6 serum levels was associated with a reduction in disease activity, the blockade of IL-6 was considered as a plausible therapeutic option in GCA [35]. Over the last ten years several case reports or small series highlighted the efficacy of the antiIL-6 receptor (tocilizumab) in both newly diagnosed and relapsing patients with GCA patients with GCA $[\mathbf{3 6 , 3 7 ]}$. In a retrospective, open-label, study, we observed that tocilizumab was useful in 22 patients with refractory and relapsing GCA [38]. All the patients from our series had been treated with high dose prednisone and 19 of them had also received conventional immunosuppressive drugs and/or biologic agents. The most common reason for using intravenous tocilizumab $(8 \mathrm{mg} / \mathrm{kg} / \mathrm{month})$ in our series was the absence of efficacy following glucocorticoid and immunosuppressive therapy [38]. Interestingly, 19 of them obtained a rapid and maintained clinical response that 
correlated with a statistically significant reduction of CRP and ESR [38]. Prednisone tapering was successfully achieved in 20 of the 22 patients [38]. Similar beneficial effects were observed in another retrospective multicenter study showed beneficial effect of tocilizumab in 28 of 34 GCA patients [39].

Two placebo-controlled trials have confirmed the efficacy of tocilizumab in patients with GCA [40,41]. The first of them was a phase 2 study in which the assessor judging clinical response was not blinded to the laboratory findings, being allowed to make changes in the treatment during the follow-up based on laboratory alterations [40]. It included 23 newly diagnosed and 7 with relapsing patients with GCA who were randomized to receive intravenous anti-IL-6 receptor tocilizumab at a dose of $8 \mathrm{mg} / \mathrm{kg}$ every 4 weeks plus prednisolone ( $n=20$ patients) or placebo infusion every 4 weeks plus prednisolone $(\mathrm{n}=10)$. The primary endpoint was the percentage of patients who achieved complete remission at a prednisolone dose of $0.1 \mathrm{mg} / \mathrm{kg} /$ day at week 12 . At that time, 17 of the 20 tocilizumab-treated GCA patients obtained complete remission whereas it only occurred in 4 of the 10 placebo-treated patients [40]. Tocilizumab use allowed performing a rapid glucocorticoid tapering followed by discontinuation after 36 weeks of from the onset of tocilizumab. The cumulative prednisolone dose at 52 weeks was significantly lower in the tocilizumab group (43 mg/kg) than in the placebo group $(110 \mathrm{mg} / \mathrm{kg})$. Relapse-free survival at 52 weeks was also significantly higher in the tocilizumab-treated patients $(85 \%)$ than in those who received placebo $(20 \%)$ [40]. A single patient undergoing tocilizumab suffered a relapse. However, relapses occurred once that tocilizumab was discontinued [40]. Regarding safety, seven (35\%) patients in the tocilizumab group and five (50\%) in the placebo group had serious adverse events $[40]$. 
This study confirmed the efficacy of tocilizumab to induce remission, prevent relapses, and decrease the cumulative glucocorticoid dose. However, from our point of view, the fact that CRP and the clinical response were considered together as a combined final endpoint could have overestimated the actual number of remissions, because tocilizumab is very effective to decrease the levels of CRP [40].

The strongest evidence of the efficacy of the anti-IL-6 receptor monoclonal antibodytocilizumab comes from the tocilizumab in GCA (GiACTA) trial [41]. The study included 251 patients from 14 countries and 76 sites, 61 of them from Europe and 15 from North America. The diagnosis of newly diagnosed cases and relapsing GCA patients was based on the results of a positive temporal-artery biopsy showing features of GCA or through imaging techniques showing large-vessel vasculitis and disease activity (cranial symptoms or PMR with an increase of acute-phase reactants). The number of patients recruited was very similar in both groups (119 newly diagnosed and 132 relapsing patients) [41]. Patients were included in one of the four following groups: a weekly dose of $162 \mathrm{mg}$ of subcutaneous tocilizumab plus a 26-week prednisone taper, a dose of $\mathrm{f} 162 \mathrm{mg}$ of subcutaneous tocilizumab given every other week along with a 26-week prednisone taper, a third group of weekly placebo-treated patients along with a 26-week prednisone taper, and a fourth group of weekly placebo-treated plus a 52-week prednisone taper.

Both groups of patients treated with tocilizumab achieved sustained remission more commonly than those placebo-treated at 52 -week. Whereas $56 \%$ of the patients receiving subcutaneous tocilizumab every week and $53 \%$ of those treated with subcutaneous tocilizumab every other week achieved remission, only $14 \%$ and $18 \%$ of the patients treated with placebo plus 26-week prednisone taper or 52-week prednisone taper reached sustained remission [41]. Besides these differences that reached statistical 
significance, patients who underwent tocilizumab therapy had less commonly relapse of the disease $(23 \%$ and $26 \%$ in those treated with tocilizumab every week or every other week) than those included in the 26 and 52-week placebo arms (68\% and 49\%, respectively). The investigators from this phase 3 trial confirmed that tocilizumab use was associated with a powerful glucocorticoid-sparing effect [41]. This effect was stronger in those patients who had experienced relapses before randomization. Patients who received tocilizumab had less serious adverse events than those treated with placebo [41]. Taking together these positive findings the weekly use of subcutaneous tocilizumab was recently approved by the United States FDA and the European Commission for the treatment of GCA.

Recent results from a real-world study of our group on 134 refractory GCA patients treated with tocilizumab support the conclusions of the GiACTA trial. We have observed a rapid and maintained clinical and laboratory improvement without differences in the GCA time course (greater than or less than 6 months), administration route (intravenous or subcutaneous) or prednisone dose at the time of the tocilizumab onset ( $\leq 15 \mathrm{mg} /$ day or $>15 \mathrm{mg} /$ day) $[\mathbf{4 2}]$. Nevertheless, we believe that the GiACTA trial has several limitations [23]. In this regard, half of the patients had short disease duration since the inclusion in the study was made within the first six weeks after the disease diagnosis. A major point of potential concern is related to be the definition of remission, which was considered as the absence of relapse (flare) plus normalization of the CRP. Since tocilizumab yields a marked reduction of acute phase reactants CRP and ESR, it is difficult to determine whether the effect mediated by this agent leads to a true remission of this vasculitis without having histopathology or imaging exams supporting such an improvement [23]. Regarding this point, we and others have observed persistent FDG uptake in large blood vessels from patients with GCA who are clinically 
asymptomatic with normal ESR and CRP [43]. Another potential limitation of the GiACTA trial was the scarce information on the effect of tocilizumab on visual loss, due to the small number of patients with unilateral or bilateral blindness at the time of inclusion. However, tocilizumab has been approved in patients with GCA and several open-label studies indicate that this biologic agent may also be useful for the management of refractory patients with other types of large vessel vasculitis. Tocilizumab therapy also yielded beneficial effects in patients with isolated aortitis and Takayasu's arteritis, who were refractory to glucocorticoids and in many cases to other immunosuppressive agents $[\mathbf{4 4 , 4 5 ]}$.

Other anti-IL-6 monoclonal antibody, different from tocilizumab, are currently under investigation in GCA. A phase-3 randomized, controlled, double-blind study using sirukumab, a fully human anti-IL-6 IgG1 antibody that blocks the IL-6 pathway a phase 3 trial (ClinicalTrials.gov Identifier: NCT02531633) was initiated but it was cancelled. Also, sarilumab, another anti-IL-6 receptor agent, is under study for its potential use and safety in GCA (ClinicalTrials.gov Identifier: NCT03600805).

\subsubsection{Abatacept}

Some patients treated with the biologic agent ipilimumab for malignant melanoma have developed GCA [46]. Ipilimumab is a monoclonal antibody directed against cytotoxic T-lymphocyte-associated antigen 4 (CTLA-4) expressed on the surface of activated T cells [46]. The recombinantIg-CTLA-4 molecule abatacept, a fusion protein composed of the crystallizable fragment of a human IgG1 and the extracellular domain of CTLA4, binds to CD80/86 blocking its interaction with CD28, which decreases T cell activation. To determine safety and efficacy to maintain remission of the intravenous abatacept in GCA, patients with newly-diagnosed or relapsing GCA were treated with 
$10 \mathrm{mg} / \mathrm{kg}$ intravenously of abatacept on days $1,15,29$, and at week 8 , together with prednisone. At week 12, 41 patients who had reached remission were blindly randomized to receive either monthly placebo intravenous infusions $(n=21)$ or monthly intravenous abatacept $(\mathrm{n}=20)$. Patients included in both study arms performed a standardized tapering prednisone dose until discontinuation at week 28 . The median duration of remission was also significantly longer in abatacept-treated patients $(9.9$ months versus 3.9 months in those who received intravenous placebo). The primary outcome of the study, relapse-free survival at 12 months, was significantly more common in patients treated with intravenous abatacept (48\%) than in those treated with placebo (31\%) [47]. Abatacept-treated patients also had longer duration of remission than those who received placebo. There were no differences in side effects between abatacept and placebo-treated groups [47].

Although these results look promising, some investigators have pointed out that due to the nonstandard design, in particular on glucocorticoid management, this study cannot be compared with the standard of care [48]. Moreover, another point that limits our ability to generalize the results of this study is the small number of patients assessed ( $\mathrm{n}=$ 41). Therefore, further studies encompassing larger number of patients are needed to confirm whether abatacept is useful as adjunctive treatment to reduce relapses or as a glucocorticoid sparing agent in patients with GCA.

\subsubsection{Ustekinumab}

IL-12 and IL-23 are two key cytokines involved in the anomalous Th1 and Th17 response occurring in the pathogenesis of GCA. Ustekinumab is a monoclonal antibody that acts targeting both IL-12 and IL-23 pathways. It leads to a disruption of the Th1 (IL-12) and Th17 (IL-23) immune responses. Following three injections of $45 \mathrm{mg}$ of 
ustekinumab given at week 0 , week 4 and week 16, a marked reduction of Th1 and Th17 cells and cytotoxic T lymphocytes at peripheral blood was observed compared to baseline in patients with refractory GCA [49]. A significant increase of Tregs was also observed [49].

An open-label study showed efficacy of ustekinumab in 14 patients with long disease duration (median 30 months) GCA who were unable to taper glucocorticoids due to active GCA with a minimum of two relapses. Ustekinumab was prescribed at $90 \mathrm{mg}$ subcutaneously at week 0 , week 4 and then every 12 weeks (median 8 months) [50]. Ustekinumab use was associated with a reduction of the glucocorticoid dose [50]. Glucocorticoids were successfully discontinued in 3 patients and in 8 patients ustekinumab allowed the discontinuation of the baseline immunosuppressive agents. Although there were not relapses while the patients were undergoing ustekinumab therapy, they were common once that ustekinumab was discontinued.

An open label study to test the safety and efficacy of ustekinumab in patients with GCA is underway (estimated study completion date March 2020).

\subsubsection{Anti-IL-1ß agents}

Since the expression of IL- $1 \beta$ mRNA is increased in the temporal arteries of patients with biopsy-proven GCA, IL-1 $\beta$ antagonists have been proposed as potential agents to be used in the management of GCA. Among them, anakinra (IL-1Ra) was successfully used at a dose of $100 \mathrm{mg}$ /day in three refractory GCA patients [51]. Because of that, a phase-III study is intended to be performed to assess the efficacy of this IL-1 $\beta$ antagonist in GCA (NCT02902731). 
Gevokizumab, a recombinant humanized anti-IL-1 $\beta$ antibody, is also under investigation for the management of GCA (European Clinical Trials Database Identifier 2013-002778-38).

\subsubsection{Novel agents: JAK/STAT inhibitors}

A great number of cytokines that are immune relevant mediators use the Janus kinase/signal transducers and activators of transcription (JAK/STAT) pathway to transduce intracellular signals [52]. Ligand binding of these immune mediators to their cell surface receptors leads to activation of associated JAKs. The activated JAKs increase their kinase activity, recruit, bind and activate STAT. The STAT molecules constitute hetero- or homo-dimers which translocate to the nucleus, inducing transcription and expression of target genes. Polymorphisms of JAK and STAT genes have been associated with autoimmune diseases [52].

STAT-1 signaling regulates the activity of vascular dendritic cells, controlling $\mathrm{T}$ cell trafficking and retention of inflammatory $\mathrm{T}$ cells in the vascular lesions $[\mathbf{5 3}, \mathbf{5 4}]$. IFN- $\gamma$ is the major inducer of STAT-1. In an experimental model in immunodeficient mice, in which animals were engrafted with human medium-sized arteries and then reconstituted with peripheral blood mononuclear cells from patients with biopsy-proven GCA, dexamethasone suppressed the innate immunity with inhibition of dendritic cell activation, IL-6 and IL-1 $\beta$ expression in the vascular lesions. However, dexamethasone spared adaptive immunity and left IFN- $\gamma$-producing Th1 unaffected [53]. The JAK/STAT-inhibitor tofacitinib, a kinase inhibitor for JAK1 and JAK3, prevented T cell accumulation in the vessel wall and suppressed IFN- $\gamma$ production and signaling in a model of vascular inflammation in human arteries engrafted into immunodeficient mice that were reconstituted with T cells and monocytes from patients with GCA [53,54]. 
Tofacitinib also led to a marked reduction of the blood levels of IFN- $\gamma[\mathbf{5 3}, \mathbf{5 4}]$.

Baricitinib is an inhibitor of 1 and JAK2 that inhibits Th17 (IL-6, IL23) and Th1 (IL-12, IFN- $\gamma$ ) pathways. In this way, a phase-II open-label pilot study with baricitinib is currently recruiting patients with relapsing GCA (NCT03026504) whose estimated primary completion results will be presented by June 2020 .

\subsection{Conclusions}

GCA is the most common vasculitis in elderly people from Western countries.

Glucocorticoids constitute the gold standard for the management of GCA. Although successful response is achieved in most patients, relapses are frequent when glucocorticoids are tapered and side effects are frequent as the result of prolonged use of glucocorticoids. For this reason, alternative therapies are often required in patients with GCA. Although MTX is the first agent used in patients with refractory GCA, the benefits associated with the use of this conventional immunosuppressive drug are mild. For this reason, novel biologic therapies that were previously used in inflammatory arthritis and other autoimmune disease have been tested for its efficacy in GCA. The first studies were conducted using anti-TNF- $\alpha$ agents. However, they yielded negative results. In contrast, the anti-IL-6 receptor tocilizumab has proved to be effective in the management of GCA. Tocilizumab appears to be especially useful in patients with refractory disease, allowing a reduction of the cumulative glucocorticoid dose and reducing the frequency of relapses of the disease. Promising results are derived from studies on abatacept and ustekinumab. The efficacy of JAK/STAT inhibitors in the management of GCA is currently under investigation.

\section{Expert Opinion}


We strongly support the use of glucocorticoids as the initial therapy for the management of GCA [23]. We and others have observed that a prednisone dose of 40-60 mg/day prednisone yields rapid improvement of most clinical features of a GCA [55,56]. Glucocorticoids at this dose prevent from the development of visual loss in GCA. However, visual recovery is very rare and not expected, even if glucocorticoids are started rapidly, after the onset of visual loss. Therefore, it is far more preferable to treat GCA before visual loss occurs. In this regard, once prednisone is started, the development of new visual loss is very uncommon.

We also agree with experts in the field on the limited effect of MTX and other conventional immunosuppressive drugs to reduce the cumulative glucocorticoid dose and induce prolonged remission of patients with GCA [22]. With respect to this, relapses are frequent when prednisone is tapered [17], and the efficacy of MTX for reduce relapses is often modest [57].

From our point of view the GiACTA trial constituted a major step forward in the management of GCA. However, we do not use the anti-IL-6 receptor tocilizumab as a single therapy without glucocorticoids. Real life data from patients with GCA have also shown that this biologic agent is effective in the management of patients who are refractory to glucocorticoids and MTX [38]. Nevertheless, autopsy results have shown persistent vascular inflammation in patients who were apparently in clinical remission following tocilizumab therapy [58].

Relapses are a major point of concern for clinicians who treat patients with GCA [17]. They are also common when tocilizumab is discontinued. The classic definition of relapse, considered to be present if a previously asymptomatic patients has again clinical features of GCA or PMR associated with an elevation of acute phase reactants, may not be useful in patients undergoing tocilizumab therapy since CRP and ESR are 
generally low in patients receiving this biologic agent. Therefore, it is possible that the requirement of increased acute phase reactants for the definition of relapse in patients included in the GiACTA trial may have overestimated the actual number of remissions, due to the favorable effect of tocilizumab to reduce CRP serum levels [40].

We feel that studies comparing the efficacy of tocilizumab versus MTX are required to confirm that this biologic agent may allow glucocorticoid discontinuation in a shorter period of time than the conventional immunosuppressive agents.

Real-life studies to determine if the use of tocilizumab is truly associated with a reduction of side effects related to glucocorticoid therapy are also needed. An issue that needs to be addressed is to determine the profile of patient who may benefit of a specific therapy. For example, GCA patients presenting with very high inflammatory response may be susceptible to the use of tocilizumab whereas those with lower inflammation, often associated with higher risk of severe ischemic complications [59], could be treated with agents that reduce the effects of IFN-gamma, other inflammatory cytokine probably involyed in the pathogenesis of this disease. We do not know if the JAK inhibitors, which have a broader effect on inflammatory pathways, may be more useful for the management of GCA than tocilizumab.

Figure 1 shows a schematic view of the authors for a stepped treatment of GCA.

\subsection{Five-year view}

The identification of genetic or serological biomarkers will help us to better identify specific patterns of the disease, to disclose GCA patients at higher risk of severe ischemic complications such as visual loss. New biologic therapies will be used soon after the diagnosis of the disease in an attempt to induce early disease remission and reduce glucocorticoid complication. The potential use of new therapies, such as JAK 
inhibitors or perhaps interferon- $r$ antagonists for the management of patients with GCA looks promising, although more studies are still needed to draw conclusions of the efficacy of these agents.

\section{Article Highlights}

- IL-6 is a pivotal proinflammatory cytokine implicated in the pathogenesis of GCA.

- Glucocorticoids are the mainstay of treatment in GCA.

- Conventional immunosuppressive agents, such as MTX, are often used in relapsing GCA patients or as glucocorticoid sparing agents. However, its efficacy is often modest.

- The anti-IL-6 receptor monoclonal antibody-tocilizumab has proved efficacy in patients with GCA to reduce relapses and the cumulative prednisone dose.

- Tocilizumab is the only biologic agent currently approved for the management of GCA.

- The use of other biologic agents and JAK inhibitors for the management of GCA is currently under investigation.

\section{Funding}

This paper was not funded.

\section{Declaration of interest}

MA Gonzalez-Gay has received grants/research supports from Abbvie, MSD, and Roche, and had consultation fees/participation in company sponsored speaker's bureau from Abbvie, Pfizer, Roche, Sanofi, Sobi, Lilly, Novartis and Celgene. R Blanco 
received grants/research supports from Abbvie, MSD and Roche, and had consultation fees/participation in company sponsored speaker's bureau from Abbvie, Pfizer, Roche, Bristol-Myers, Janssen and MSD. S Castañeda has received fees for lectures and honorary for participation in advisory boards from Abbvie, Amgen, Eli-Lilly, MSD, Pfizer, Roche and Sobi. The authors have no other relevant affiliations or financial conflict with the subject matter or materials discussed in the manuscript apart from those disclosed.

\section{Reviewer Disclosures}

Peer reviewers on this manuscript have no relevant financial relationships or otherwise to disclose.

\section{Bibliography}

Papers of special note have been highlighted as either of interest $(\bullet)$ or of considerable interest $(\bullet)$ to readers.

*1. Gonzalez-Gay MA, Vazquez-Rodriguez TR, Lopez-Diaz MJ, et al. Epidemiology of giant cell arteritis and polymyalgia rheumatica. Arthritis Rheum 2009; 61:1454-61.

* Review article that discussed in depth the epidemiology of GCA.

**2. Salvarani C, Cantini F, Boiardi L, Hunder GG. Polymyalgia rheumatica and giantcell arteritis. N Engl J Med 2002; 347:261-71.

**Review article on pathophysiology, clinical features and treatment of GCA.

3. Gonzalez-Gay MA, Miranda-Filloy JA, Lopez-Diaz MJ, et al. Giant cell arteritis in northwestern Spain: a 25-year epidemiologic study. Medicine (Baltimore) 2007; 86:618. 
4. Weyand CM, Goronzy JJ. Clinical practice. Giant-cell arteritis and polymyalgia rheumatica. N Engl J Med 2014; 371:50-7.

5. Gonzalez-Gay MA. The diagnosis and management of patients with giant cell arteritis. J Rheumatol 2005; 32:1186-8.

*6. González-Gay MA, Pina T. Giant cell arteritis and polymyalgia rheumatica: an update. Curr Rheumatol Rep 2015; 17:6.

*An update of the epidemiology, clinical features diagnosis and management of GCA.

*7. Gonzalez-Gay MA, Castañeda S, Llorca J. Giant Cell Arteritis: Visual Loss Is Our Major Concern. J Rheumatol 2016; 43:1458-61.

*Article that emphasizes the relevance of visual ischemic complications in the outcome of patients with GCA.

8. Nuenninghoff DM, Hunder GG, Christianson TJ, McClelland RL, Matteson EL. Incidence and predictors of large-artery complication (aortic aneurysm, aortic dissection, and/or large-artery stenosis) in patients with giant cell arteritis: a populationbased study over 50 years. Arthritis Rheum 2003; 48:3522-31.

9. Gonzalez-Gay MA, Garcia-Porrua C, Piñeiro A, Pego-Reigosa R, Llorca J, Hunder GG. Aortic aneurysm and dissection in patients with biopsy-proven giant cell arteritis from northwestern Spain: a population-based study. Medicine (Baltimore) 2004; $83: 335-41$

10. García-Martínez A, Arguis P, Prieto-González S, Espígol-Frigolé G, Alba MA, Butjosa M, et al. Prospective long term follow-up of a cohort of patients with giant cell arteritis screened for aortic structural damage (aneurysm or dilatation). Ann Rheum Dis $2014 ; 73: 1826-32$.

**11. González-Gay MA, Matteson EL, Castañeda S. Polymyalgia rheumatica. Lancet 2017; 390(10103):1700-12. 


\section{** Review on the epidemiology, clinical spectrum, diagnosis and treatment of patients with PMR.}

12. Gonzalez-Gay MA, Vazquez-Rodriguez TR, Gomez-Acebo I, et al. Strokes at time of disease diagnosis in a series of 287 patients with biopsy-proven giant cell arteritis. Medicine (Baltimore) 2009; 88:227-35.

13. Prior JA, Ranjbar H, Belcher J, et al. Diagnostic delay for giant cell arteritis - a systematic review and meta-analysis. BMC Med 2017; 15:120.

14. Dasgupta B. Giant Cell Arteritis Guideline Development Group. Concise guidance: diagnosis and management of giant cell arteritis. Clin Med (Lond) 2010; 10:381-6. 15. Gonzalez-Gay MA, Lopez-Diaz MJ, Barros S, et al. Giant cell arteritis: laboratory tests at the time of diagnosis in a series of 240 patients. Medicine (Baltimore) 2005; $84: 277-90$.

16. Proven A, Gabriel SE, Orces C, O'Fallon WM, Hunder GG. Glucocorticoid therapy in giant cell arteritis: duration and adverse outcomes. Arthritis Rheum 2003; 49:703-8. 17. Martinez-Lado L, Calviño-Díaz C, Piñeiro A, et al. Relapses and recurrences in giant cell arteritis: a population-based study of patients with biopsy-proven disease from northwestern Spain. Medicine (Baltimore) 2011; 90:186-93.

*18. Roncato C, Allix-Béguec C, Brottier-Mancini E, Gombert B, Denis G. Diagnostic performance of colour duplex ultrasonography along with temporal artery biopsy in suspicion of giant cell arteritis. Clin Exp Rheumatol 2017; 35 Suppl 103:119-22.

*The authors consider that in patients with patients with suspicion of GCA color duplex ultrasonography may be used as first line examination followed by temporal artery biopsy if color duplex ultrasonography yields negative results. **19. Dejaco C, Ramiro S, Duftner C, et al. EULAR recommendations for the use of imaging in large vessel vasculitis in clinical practice. Ann Rheum Dis 2018; 77:636-43. 
**The authors described the European League Against Rheumatism

recommendations on the role of the imaging techniques in the diagnosis and monitoring of patients in whom a large vessel vascultis is suspected.

20. Loricera J, Blanco R, Hernández JL, et al. Non-infectious aortitis: a report of 32 cases from a single tertiary centre in a 4-year period and literature review. Clin Exp Rheumatol 2015; 33(2 Supp1 89):S-19-31.

21. Brack A, Martinez-Taboada V, Stanson A, Goronzy JJ, Weyand CM. Disease pattern in cranial and large-vessel giant cell arteritis. Arthritis Rheum 1999; 42:311-7. **22. Yates M, Loke YK, Watts RA, MacGregor AJ. Prednisolone combined with adjunctive immunosuppression is not superior to prednisolone alone in terms of efficacy and safety in giant cell arteritis: meta-analysis. Clin Rheumatol 2014; 33:227-36. **Very interesting meta-analysis of published data of the effectiveness of drug treatment in patients with GCA. The results from this meta-analysis showed that the use of adjunct agents including conventional immunosuppressive drugs and anti-TNF agents was not associated with improved outcome.

*23. González-Gay MA, Pina T, Prieto-Peña D, Calderon-Goercke M, Blanco R, Castañeda S. Current and emerging diagnosis tools and therapeutics for giant cell arteritis. Expert Rey Clin Immunol 2018; 14:593-605.

* Review article on the diagnosis and management of GCA. Information on glucocorticoids and conventional immunosuppressive therapies used in patients with GCA was extensively discussed.

24. Weyand CM, Hicok KC, Hunder GG, Goronzy JJ. Tissue cytokine patterns in patients with polymyalgia rheumatica and giant cell arteritis. Ann Intern Med 1994; 121:484-91.

25. Hernández-Rodríguez J, Segarra M, Vilardell C, Sánchez M, García-Martínez A, Esteban MJ, et al. Tissue production of pro-inflammatory cytokines (IL-1beta, TNF- 
alpha and IL-6) correlates with the intensity of the systemic inflammatory response and with corticosteroid requirements in giant-cell arteritis. Rheumatology (Oxford) 2004; 43:294-301.

26. Field M, Cook A, Gallagher G. Immuno-localisation of tumour necrosis factor and its receptors in temporal arteritis. Rheumatol Int 1997; 17:113-8.

*27. Hoffman GS, Cid MC, Rendt-Zagar KE, et al. Infliximab for maintenance of glucocorticosteroid-induced remission of giant cell arteritis: a randomized trial. Ann Intern Med 2007; 146:621-30.

\section{*The largest clinical trial on anti-TNF therapy in GCA. It did not show efficacy of this agent in patients with GCA.}

28. Seror R, Baron G, Hachulla E, et al. Adalimumab for steroid sparing in patients with giant-cell arteritis: results of a multicentre randomized controlled trial. Ann Rheum Dis 2014; 73:2074-81.

29. Martínez-Taboada VM, Rodríguez-Valverde V, Carreño L, et al. A double-blind placebo controlled trial of etanercept in patients with giant cell arteritis and corticosteroid side effects. Ann Rheum Dis 2008; 67:625-30.

30. Weyand CM, Schonberger J, Oppitz U, Hunder NN, Hicok KC, Goronzy JJ. Distinct vascular lesions in giant cell arteritis share identical T cell clonotypes. J Exp Med 1994; 179:951-60.

31. Wagner AD, Goronzy JJ, Weyand CM. Functional profile of tissue-infiltrating and circulating CD68+ cells in giant cell arteritis. Evidence for two components of the disease. J Clin Invest 1994; 94:1134-40.

32. Weyand CM, Hicok KC, Hunder GG, Goronzy JJ. Tissue cytokine patterns in patients with polymyalgia rheumatica and giant cell arteritis. Ann Intern Med 1994; 121:484-91. 
33. Garcia-Martinez A, Hernandez-Rodriguez J, Espigol-Frigole G, et al. Clinical relevance of persistently elevated circulating cytokines (tumor necrosis factor alpha and interleukin-6) in the long-term followup of patients with giant cell arteritis. Arthritis Care Res 2010; 62:835-41.

**34. Dasgupta B, Panayi GS. Interleukin-6 in serum of patients with polymyalgia rheumatica and giant cell arteritis. Br J Rheumatol 1990; 29:456-8.

** Clinical study that highlighted for first time the relevance of IL-6 in GCA. 35. Unizony S, Stone JH, Stone JR. New treatment strategies in large-vessel vasculitis. Curr Opin Rheumatol 2013; 25:3-9.

36. Seitz M, Reichenbach S, Bonel HM, Adler S, Wermelinger F, Villiger PM. Rapid induction of remission in large vessel vasculitis by IL-6 blockade. A case series. Swiss Med Wkly 2011; 141:w13156.

37. Salvarani C, Magnani L, Catanoso M, et al. Tocilizumab: a novel therapy for patients with large-vessel vasculitis. Rheumatology (Oxford) 2012; 51:151-6.

*38. Loricera J, Blanco R, Hernández JL, et al. Tocilizumab in giant cell arteritis: Multicenter open-label study of 22 patients. Semin Arthritis Rheum 2015; 44:717-23.

*Open-label retrospective study on 22 patients with GCA showing that tocilizumab was effective in refractory GCA. The use of tocilizumab led to clinical improvement in most cases. Significant reduction of acute phase proteins prednisone dose was also achieved.

39. Régent A, Redeker S, Deroux A, et al. Tocilizumab in Giant Cell Arteritis: A Multicenter Retrospective Study of 34 Patients. J Rheumatol 2016; 43:1547-52. **40. Villiger PM, Adler S, Kuchen S, et al. Tocilizumab for induction and maintenance of remission in giant cell arteritis: a phase 2, randomised, double-blind, placebo-controlled trial. Lancet 2016; 387(10031):1921-7. 
**First placebo-controlled trial showing the efficacy of intravenous tocilizumab to achieve disease remission, reduce relapses and cumulative glucocorticoid dose in patients with GCA.

**41. Stone JH, Tuckwell K, Dimonaco S, et al. Trial of Tocilizumab in Giant cell Arteritis. N Engl J Med 2017; 377:317-28.

**The strongest evidence of the beneficial effect of tocilizumab in GCA.

Subcutaneous tocilizumab along with glucocorticoids was more effective than glucocorticoids in monotherapy in the management of GCA. Tocilizumab yielded a statistically significant reduction in the cumulative glucocorticoid dose in the first 52 weeks of treatment. Patients undergoing tocilizumab therapy had longer duration of remission free of relapses than those treated with placebo.

42. Calderon-Goercke M, Loricera J, Prieto-Peña D, et al. Tocilizumab in Giant Cell Arteritis. National Multicenter Study of 134 Patients of Clinical Practice. Abstract Supplement 2018 ACR/ARHP Annual Meeting. Arthritis Rheumatol 2018; 70 (Suppl 9): Abstract Number 2752.

43. Prieto-Peña D, Loricera J, Calderon-Goercke M, et al. Giant Cell Arteritis in Treatment with Tocilizumab. Evolution of Vascular FDG Uptake on PET/CT. Abstract Supplement 2018 ACR/ARHP Annual Meeting. Arthritis Rheumatol 2018; 70 (Suppl 9): Abstract Number 2748.

44. Loricera J, Blanco R, Castañeda S, et al. Tocilizumab in refractory aortitis: study on 16 patients and literature review. Clin Exp Rheumatol 2014; 32(3 Suppl 82):S79-89. *45. Loricera J, Blanco R, Hernández JL, et al. Tocilizumab in patients with Takayasu arteritis: a retrospective study and literature review. Clin Exp Rheumatol 2016; 34(3 Suppl 97):S44-53.

*Open-label study showing beneficial effect of tocilizumab in relapsing Takayasu arteritis refractory to glucocorticoids and other immunosuppressive therapies. 
46. Goldstein BL, Gedmintas L, Todd DJ. Drug-associated polymyalgia rheumatica/giant cell arteritis occurring in two patients after treatment with ipilimumab, an antagonist of CTLA-4. Arthritis Rheumatol 2014; 66:768-9.

*47. Langford CA, Cuthbertson D, Ytterberg SR, et al. A randomized, double blind trial of Abatacept (CTLA-4Ig) for the treatment of Giant Cell Arteritis. Arthritis Rheumatol 2017; 69:837-45.

*First double-blind study showing that abatacept may be useful in patients with GCA. However, the place of abatacept as adjunctive treatment to obtain superior effectiveness against relapses or as a glucocorticoid $\square$ sparing agent remains to be firmly proven by comparison with standard management.

48. De Boysson H, Aouba A. Abatacept as Adjunctive Therapy for the Treatment of Giant Cell Arteritis: Comment on the Article by Langford et al. Arthritis Rheumatol 2017; 69:1504.

*49. Samson M, Ghesquière T, Berthier S, Bonnotte B. Ustekinumab inhibits Th1 and Th17 polarisation in a patient with giant cell arteritis. Ann Rheum Dis 2018; 77:e6. doi: 10.1136/annrheumdis-2017-211622.

*Ustekinumab modulated the Th1/Th17/Treg imbalance in patients with refractory GCA.

*50. Conway R, O'Neill L, O'Flynn E, et al. Ustekinumab for the treatment of refractory giant cell arteritis. Ann Rheum Dis 2016; 75:1578-9.

*Small open-label study that supported the use of ustekinumab in refractory GCA. 51. Ly KH, Stirnemann J, Liozon E, Michel M, Fain O, Fauchais AL. Interleukin-1 blockade in refractory giant cell arteritis. Joint Bone Spine 2014; 81:76-8.

52. Banerjee S, Biehl A, Gadina M, Hasni S, Schwartz DM. JAK-STAT signaling as a target for inflammatory and autoimmune diseases: current and future prospects. Drugs 2017; 77:521-46. 
53. Hartmann B, Liao J, Weisman MH, Warrington KJ, Goronzy JJ, Weyand CM. The STAT1 Signaling Pathway In Giant Cell Arteritis. Meeting: 2013 ACR/ARHP Annual Meeting; Abstract Number: 1691.

**54. Zhang H, Watanabe R, Berry GJ, Tian L, Goronzy JJ, Weyand CM. Inhibition of JAK-STAT Signaling Suppresses Pathogenic Immune Responses in Medium and Large Vessel Vasculitis. Circulation 2018; 137:1934-48.

**The use of the JAK/STAT inhibitor tofacitinib prevented Th1 cell accumulation in the vessel wall and reduced interferon-gamma production in an experimental model engrafted with human medium-sized arteries in immunodeficient mice. 55. Gonzalez-Gay MA, Martinez-Dubois C, Agudo M, Pompei O, Blanco R, Llorca J. Giant cell arteritis: epidemiology, diagnosis, and management. Curr Rheumatol Rep 2010; 12:436-42.

56. Gonzalez-Gay MA, Blanco R, Rodriguez-Valverde V, et al. Permanent visual loss and cerebrovascular accidents in giant cell arteritis: predictors and response to treatment. Arthritis Rheum 1998; 41:1497-504.

*57. Mahr AD, Jover JA, Spiera RF, et al. Adjunctive methotrexate for treatment of giant cell arteritis: an individual patient data meta-analysis. Arthritis Rheum 2007; $56: 2789-97$.

*Meta-analysis showing a modest role for methotrexate (10-15 mg/week) in patients with GCA.

58. Unizony S, Arias-Urdaneta L, Miloslavsky E, et al. Tocilizumab for the treatment of large-vessel vasculitis (giant cell arteritis, Takayasu arteritis) and polymyalgia rheumatica. Arthritis Care Res (Hoboken) 2012; 64:1720-9.

59. Lopez-Diaz MJ, Llorca J, Gonzalez-Juanatey C, Peña-Sagredo JL, Martin J, Gonzalez-Gay MA. The erythrocyte sedimentation rate is associated with the development of visual complications in biopsy-proven giant cell arteritis. Semin 
Arthritis Rheum 2008; 38:116-23.

\section{FIGURE LEGEND}

Figure 1. Schematic view of the authors for a stepped treatment of giant cell arteritis. Abbreviations: JAK/STAT: Janus kinase/signal transducers and activators of transcription; OP: osteoporosis. 


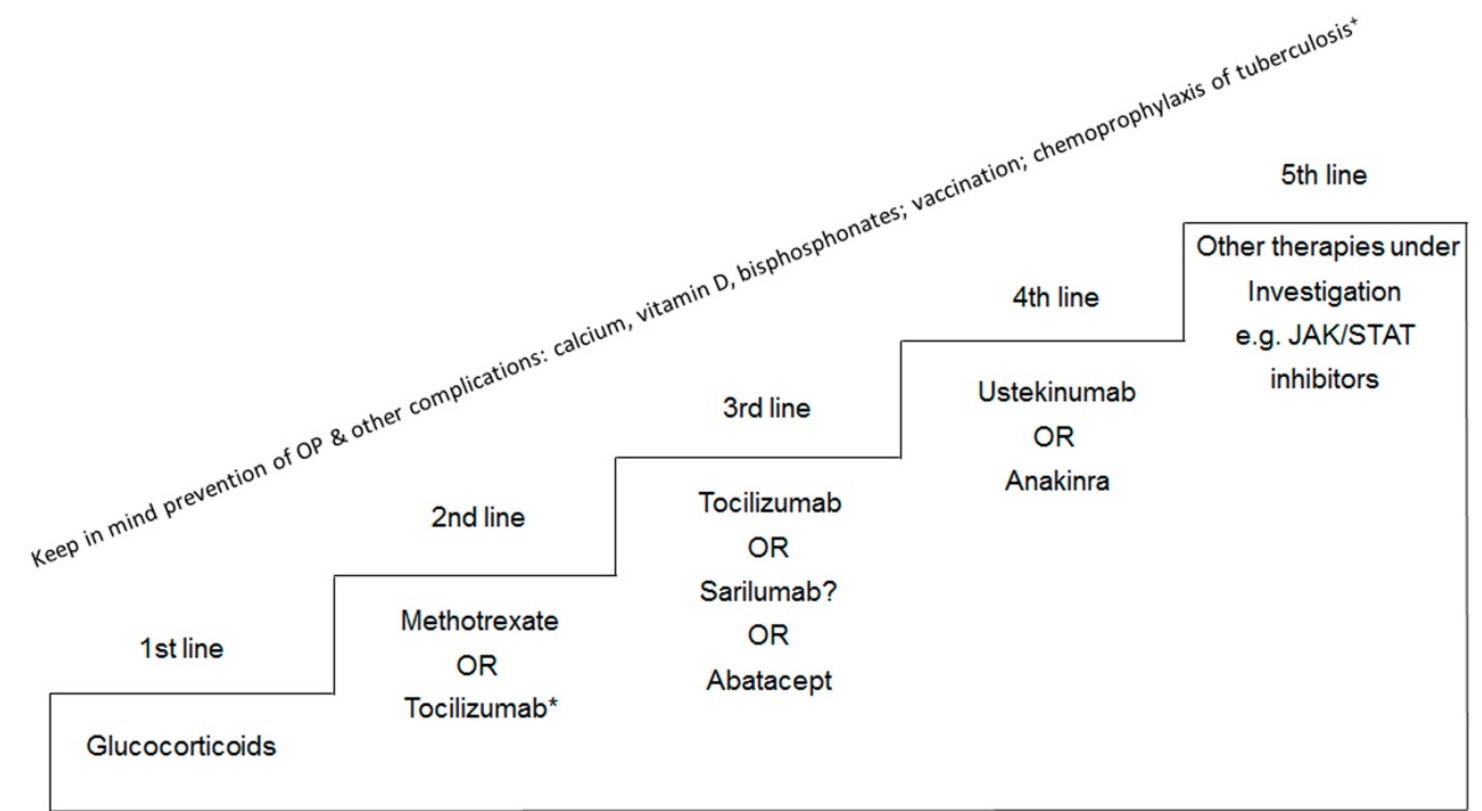

*Tocilizumab can be used as a first-line therapy to reduce the cumulative glucocorticoid dose in newly diagnosed GCA patients who have suffered adverse effects from glucocorticoids, patients with diabetes, osteoporosis with fractures or in those in whom severe side-effects related to glucocorticoids may occur.

+ Chemoprophylaxis of tuberculosis: If required. 